\title{
Impact of the hybrid reactive power compensator on the power grid used a fuzzy PI regulator
}

\author{
Abdelkader Rahmouni \\ Electrical Engineering Department, Faculty of Technology, Tahri Mohammed Bechar University, Bechar, Algeria
}

\begin{tabular}{l}
\hline \hline Article Info \\
\hline Article history: \\
Received Feb 6, 2020 \\
Revised Dec 2, 2020 \\
Accepted Jan 9, 2021 \\
\hline
\end{tabular}

\section{Keywords:}

FACTS

Fuzzy PI

Harmonics filters

HSVC

TCR

TSC

\begin{abstract}
The work presented in this article is a contribution to the problem of controlling reactive powers and voltages in an electrical network. Among these control tools, the static reactive power compensator (SVC) was chosen because of its simplicity of control. SVC is one of the alternative flexible current transmission systems (FACTS) devices which help to solve the problems encountered in the operation of electrical networks, either on the distribution side or on the transport side. To increase its compensation efficiency in the face of harmonic currents which cause voltage distortion, we have introduced a three-phase harmonic filter. This new hybrid SVC is used to control the reactive power, the voltage and in addition to reduce the voltage distortion and the correction of the power factor in the electrical energy transport network. In order to improve its efficiency, two voltage regulation systems have been chosen in the control system for this compensator, the fuzzy PI regulator and the PIP regulator.
\end{abstract}

This is an open access article under the CC BY-SA license.

\section{Corresponding Author:}

Abdelkader Rahmouni

Electrical Engineering Department, Faculty of Technology

Tahri Mohammed Bechar University

Bechar, Algeria

Email: rahmouni.a001@gmail.com

\section{INTRODUCTION}

The increasing use of electrical energy in the economic, social and industrial life of each country is causing more and more problems of disturbances, overvoltages, voltage drops and harmonics in electrical networks. The rapid development of power electronics has had a considerable effect on improving the operating conditions of electrical networks by controlling their parameters by introducing control devices based on advanced very high power electronic components known as the name of FACTS: Alternative Current Transmission Systems [1]-[3].

The research reported in this article is motivated by the desire to improve the control of reactive powers and voltages to further reduce the distortion of voltage and current in an electrical energy transport network by means of a FACTS device, the hybrid static Var Compensator SVC. This new SVC hybrid compensator is made up of SVC based on the controllable power electronics coponents [4], and the threephase harmonic filters used to eliminate different order harmonic currents and thus maintain the stable state of the transient voltage within the desired limits. The SVC injects or absorbs reactive power into the busbar where it is installed to meet the demand for reactive power from the load. It allows flexible and continuous control of the busbar tension [5], [6].

In this work, this hybrid SVC is used to control reactive power and voltage in an electrical power transmission network, using two voltage control systems in the control system of this compensator to improve its performance the first is the fuzzy PI regulator and the second is the PIP regulator [7]-[9]. 
Harmonic filters reduce harmonic currents by diverting them into low impedance paths so they reduce the THD (Harmonic distortion rate) of the voltage at the same time.

\section{STATIC REACTIVE POWER COMPENSATOR HYBRID (HSVC)}

The SVC reactive power compensator hybrid is a device used to keep the transient and stationary voltage within the desired limits in the presence of harmonic currents in the network. It injects reactive power into the bar where it is connected in order to satisfy the demand for reactive power of the load. In general, the SVC hybrid is a combination of thyristor-controlled reactors (TCR), TSC (thyristor-switched capacitors), and three-phase harmonic filters. These are three constituents of the HSVC are:

\subsection{Thyristors controlled reactance (TCR)}

The TCR is one of the most important components of an SVC. It provides fast, continuous control of reactive power on the power grid. The Thyristor-Controlled Reactor (TCR) thyristor controlled reactor has a bidirectional thyristor valve $\mathrm{T}_{1}$ and $\mathrm{T}_{2}$ connected in series with a fixed inductance coil $\mathrm{L}$, shown in Figure 1. The thyristors are switched on with a certain ignition angle $\alpha$ and drive alternately over half a period. The ignition angle $\alpha$ varies from $90^{\circ}$ to $180^{\circ}$. In full conduction $\left(\alpha=90^{\circ}\right)$, the current is essentially reactive and sinusoidal, and when $\alpha=180^{\circ}$, one is in null conduction [10]-[12].

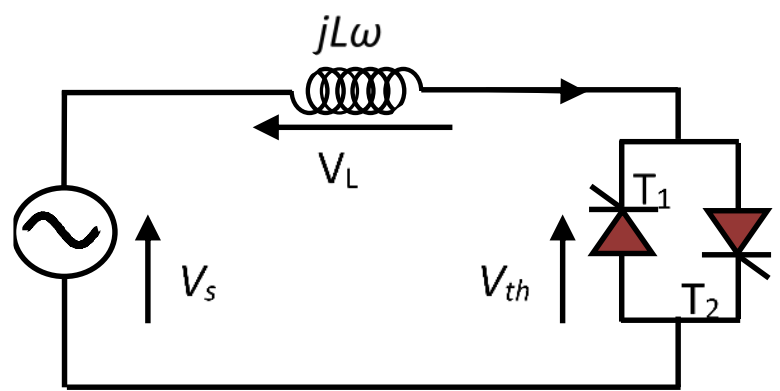

Figure 1. Single-phase circuit of a TCR

Relationship between the ignition angle $\alpha$ and $B_{\max }$ the susceptance $B_{T V R}$ of inductance L: Let the source voltage $\mathrm{v}_{\mathrm{s}}$ given by the following relation:

$$
v_{s}(t)=V_{m} \sin (\omega t)
$$

From Figure 1 the equation of the voltage of the circuit is:

$$
L \frac{d i_{T C R}(t)}{d t}-v_{S}(t)
$$

With the initial condition $(\omega \mathrm{t} 0=\alpha)$, the solution of this equation is given by:

$$
i_{T C R}(t)=\frac{1}{L} \int_{\alpha / \omega}^{t} V_{s}(t) d t
$$

We then get:

$$
i_{T C R}(t)=-\frac{V_{m}}{\omega L}(\cos \alpha-\cos \omega t)
$$

According to the Fourier analysis, the fundamental component $\mathrm{i}_{\mathrm{TCR}}(\mathrm{t})$ of the current is given by:

$$
i_{1 T C R}(t)=a_{1} \cos \omega t+b_{1} \cos \omega t
$$

From (4), the current is a function pair $\mathrm{i}_{\mathrm{TCR}}(\mathrm{t})=\mathrm{i}_{\mathrm{TCR}}(-\mathrm{t})$, that is to say $\mathrm{b}_{1}=0$. The coefficient $\mathrm{a}_{1}$ is: 


$$
a_{1} t=\frac{4 \omega}{\pi} \int_{\alpha / \omega}^{\pi / \omega}-\frac{V_{m}}{L \omega}(\cos \alpha-\cos \omega t) \cdot \cos \omega t \cdot d t
$$

The magnitude of the fundamental current is the result of (6):

$$
\begin{aligned}
& I_{1 T C R}(t)=a_{1}(t)=\frac{V_{m}}{\omega L}\left(\frac{2 \pi-2 \alpha+\sin 2 \alpha}{\pi}\right) \\
& I_{1 T C R}(t)=V_{m} B_{T C R}(\alpha)
\end{aligned}
$$

This relationship can be written as:

$$
\begin{aligned}
& B_{T C R}(\alpha)=B_{\max }\left(\frac{2 \pi-2 \alpha+\sin 2 \alpha}{\pi}\right) \\
& B_{\max }=\frac{1}{\omega L}=\frac{1}{X_{l}}
\end{aligned}
$$

\subsection{Thyristor switched capacitor (TSC)}

The thyristor-switched capacitor TSC is composed of a fixed capacitor C plus an attenuation inductance coil $\mathrm{L}$ connected in series with a bidirectional thyristor valve Figure 2 . The function of the switch is to turn on and off the capacitor for an integer number of half cycles of the applied voltage. The capacitor is thus not controlled in phase, but simply switched on and off. The attenuation inductance serves to limit the current in case of abnormal operation and to avoid resonance with the grating at particular frequencies. To have a minimum of transient disturbances, the switching times are chosen so that the voltage across the thyristors is minimal. Interlocking is therefore performed when the residual voltage of the capacitor is equal to the instantaneous network voltage [13]-[16].

The capacitor can be switched with a minimum of transient if the thyristor is on (state on), at the instant when the voltage $v_{C}$ of the capacitor and the voltage $v_{s}$ of the network have the same value. Since the susceptance is fixed, the current in the TSC varies linearly with voltage V (which explains the absence of harmonics on the TSC). Typically, TSC type SVC contains $\mathrm{n}$ bench of TSCs mounted in parallel. The susceptance is adjusted by controlling the number of parallel capacitors in conduction. Each capacitor always drives for an integral number of half cycles.

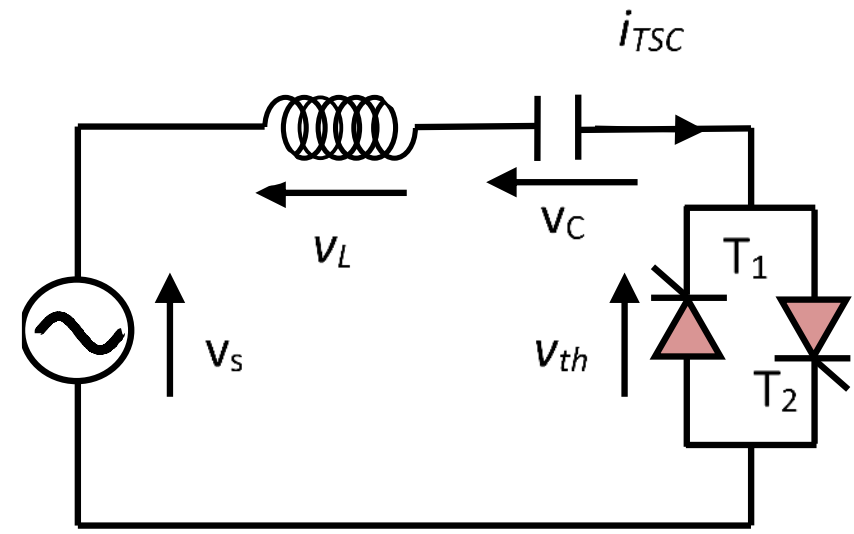

Figure 2. Single-phase circuit of a TSC with series inductance

\subsection{Three-phase harmonic filters (HF)}

Three-phase harmonic filters (built of RLC elements) Figure 3 are shunt elements that are used in power systems for decreasing voltage distortion and for power factor correction. Nonlinear elements such as power electronic converters generate harmonic currents or harmonic voltages, which are injected into power system. The resulting distorted currents flowing through system impedance produce harmonic voltage distortion. Harmonic filters reduce distortion by diverting harmonic currents in low impedance paths. 
Harmonic filters are designed to be capacitive at fundamental frequency, so that they are also used for producing reactive power required by converters and for power factor correction.

The most commonly used filter types are [17], [18]:

a) Band-pass filters, which are used to filter lowest order harmonics such as 5th, 7th, 11th, 13th, etc. Bandpass filters can be tuned at a single frequency (single-tuned filter) or at two frequencies (double-tuned filter).

b) High-pass filters, which are used to filter high-order harmonics and cover a wide range of frequencies. A special type of high-pass filter, the C-type high-pass filter, is used to provide reactive power and avoid parallel resonances. It also allows filtering low order harmonics (such as 3rd), while keeping zero losses at fundamental frequency.

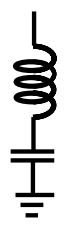

Single-tuned

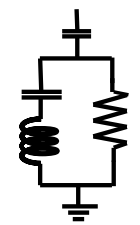

C-type High-pass

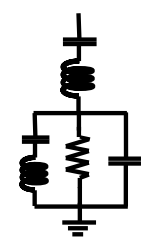

Double-tuned

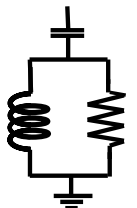

High-pass

Figure 3. Shows the different types of three-phase RLC harmonic filter

The Frequency-Domain Response of three-phase harmonic filters HF is given according to its four components. The frequency of the single-tuned filter is $\mathrm{fn}=5 * 60 \mathrm{~Hz}$ (filtering of the 5 th order harmonic), of the C-type high-pass filter is $\mathrm{fn}=3 * 60 \mathrm{~Hz}$ (filtering of the 3rd order harmonic), of the Double - tuned filter are $\mathrm{fn} 1=11 * 60 \mathrm{~Hz}$ and $\mathrm{fn} 2=13 * 60 \mathrm{~Hz}$ (filtering of the $11 \mathrm{rd}$ and $13 \mathrm{rd}$ order harmonics) and the high-pass filter is $\mathrm{fn}=24 * 60 \mathrm{~Hz}$ (filtering of the $24 \mathrm{rd}$ order harmonic). This frequency domain and the phase of this filter are shown in Figure 4.

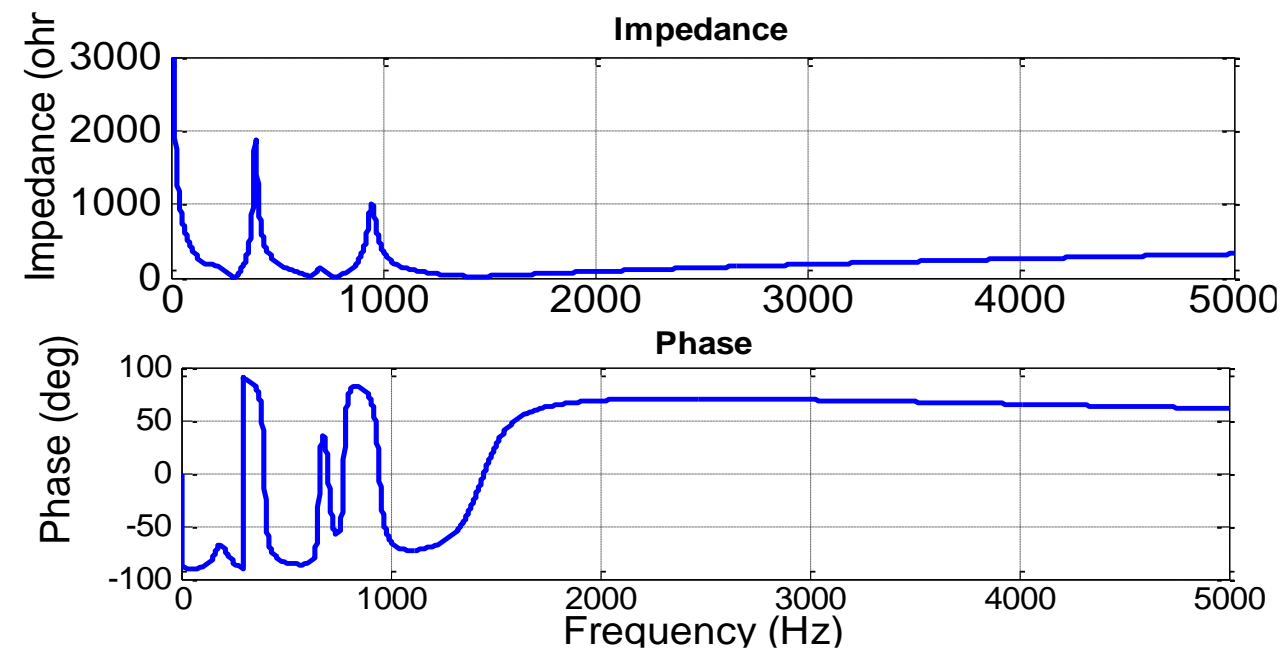

Figure 4. Frequency-domain response and phase of three-phase harmonic filters HF

\section{SVC COMMAND}

The SVC adjusts these values automatically in response to changes in network operating conditions as it has possibilities to establish capacitive or inductive currents of this network. The operation of an SVC is based on the main function of the essential elements that constitute this compensator such as the measuring circuits, the voltage regulator, the comparators, and the conduction circuits of TCR and TSC.The control model of an SVC is shown in Figure 5 with a measured voltage regulator. In this work I will compare the results for two regulators, the PIP and the PI fuzzy. 


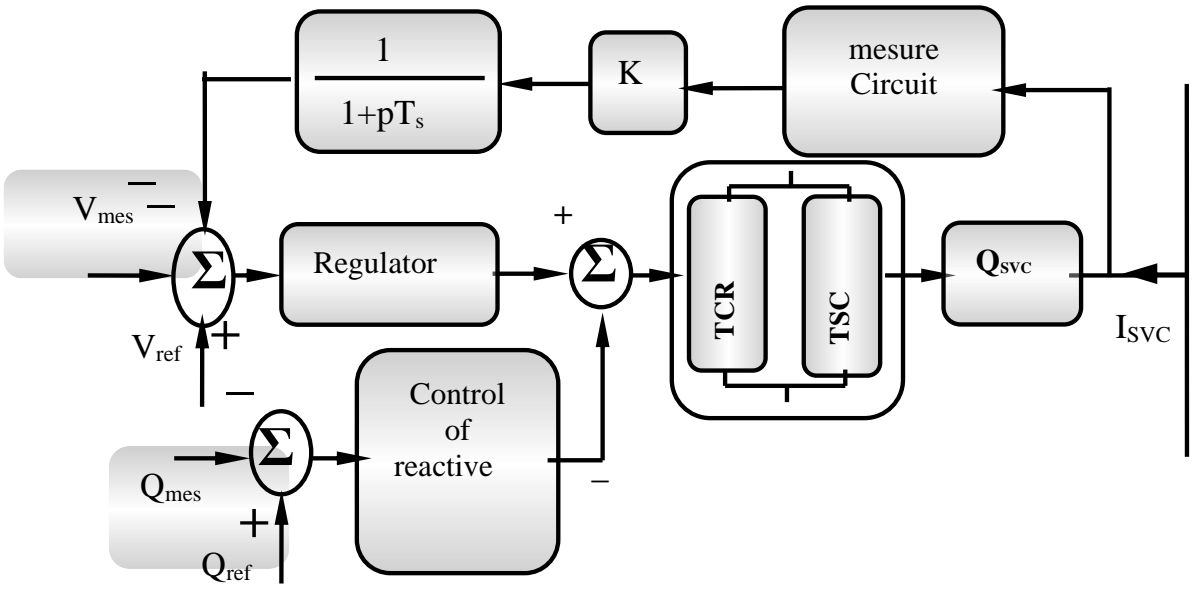

Figure 5. Simplified block diagram for controlling an SVC

\subsection{PIP regulator}

The proposed PIP regulator is an IP regulator associated in parallel with a proportional regulator $\mathrm{P}$ [19], [20]. The block diagram of the control voltage $\mathrm{V}_{\text {mes }}$ including the PIP controller is illustrated in Figure 6.

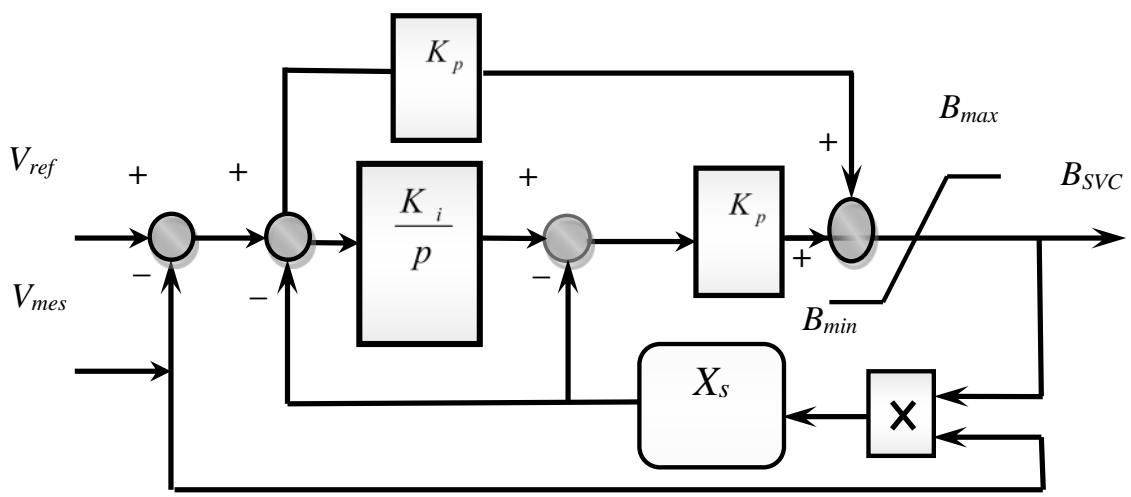

Figure 6. PIP regulator scheme for the rms value $\left(\mathrm{V}_{\text {mes }}\right)$ of the network voltage

where $\mathrm{K}_{\mathrm{i}}$ is an integral gain, and $\mathrm{K}_{\mathrm{p}}$ a proportional gain.

$\mathrm{X}_{\mathrm{s}}$ is a reactance obtained from the following relation: $\mathrm{V}_{\mathrm{mes}}=\mathrm{V}_{\mathrm{ref}-} \mathrm{X}_{\mathrm{s}} \cdot \mathrm{I}_{\mathrm{SVC}}$

\subsection{Fuzzy PI regulator}

The fuzzy PI regulator is given in Figure 7. The basic diagram of the PI-fuzzy regulator rests on the structure of a traditional regulator PI [21]-[24]. On found in input and output of the controller fuzzy gains known as "factors of "scale" which allows to change the sensitivity of the fuzzy controller without changing the structure, the input and output variables being normalized. 


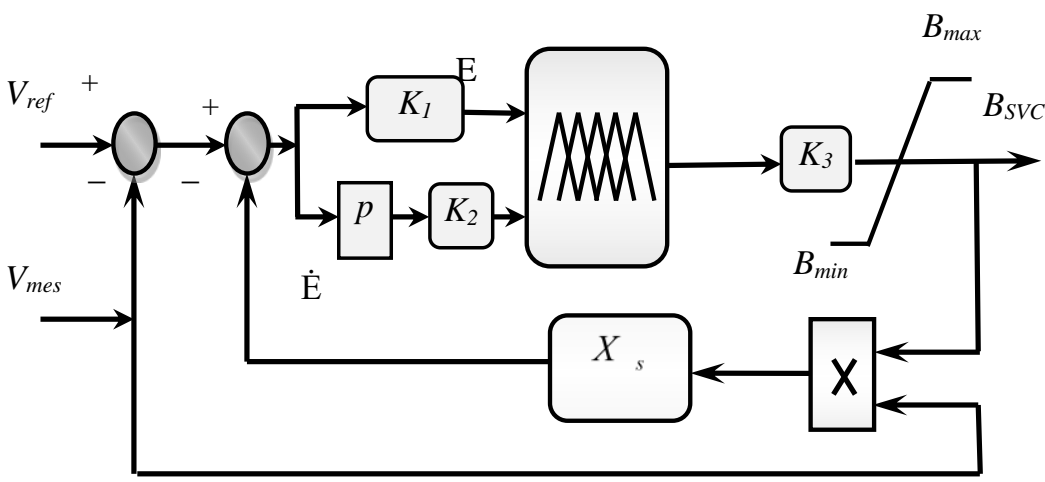

Figure 7. Regulator scheme of the rms value $\left(\mathrm{V}_{\text {mes }}\right)$ of the inter-phase network voltage

The error : $E=\left(V_{r e f}-V_{m e s}\right)-X_{s} \cdot I_{S V C}$

$\dot{\mathrm{E}}$ : the derivative of the error.

We find in the input and output of the fuzzy controller gains called "scale factors" that can change the sensitivity of the fuzzy controller without changing the structure. Each linguistic variable (E, E, u) is characterized by seven terms of fuzzy subsets: NG: negative grand; NM: negative Medium; NP: negative Small; EZ: about zero; PG: Positive grand; PM: Positive Medium; PP: positive Small. The rule base for the fuzzy logic controller can be framed by taking possible combinations of the input variables as presented in Table 1.

Table 1. Inference rule of the PI fuzzy regulator managing the output

\begin{tabular}{cccccccc}
\hline$E^{2}$ & $N G$ & $N M$ & $N P$ & $E Z$ & $P P$ & $P M$ & $P G$ \\
\hline$N G$ & $N G$ & $N G$ & $N G$ & $N G$ & $N M$ & $N P$ & $E Z$ \\
$N M$ & $N G$ & $N G$ & $N G$ & $N M$ & $N P$ & $E Z$ & $P P$ \\
$N P$ & $N G$ & $N G$ & $N M$ & $N P$ & $E Z$ & $P P$ & $P M$ \\
$E Z$ & $N G$ & $N M$ & $N P$ & $E Z$ & $P P$ & $P M$ & $P G$ \\
$P P$ & $N M$ & $N P$ & $E Z$ & $P P$ & $P M$ & $P G$ & $P G$ \\
$P M$ & $N P$ & $E Z$ & $P P$ & $P M$ & $P G$ & $P G$ & $P G$ \\
$P G$ & $E Z$ & $P P$ & $P M$ & $P G$ & $P G$ & $P G$ & $P G$ \\
\hline
\end{tabular}

\section{SIMULATIONS AND DISCUSSION OF RESULTS}

The different parts of the HSVC studied previously, the electrical network and a non-linear load (high voltage AC/DC converters HVDC with 12-pulse thyristors) are simulated on MATLAB/Simulink. The structure studied in Figure 8 is composed of the Hybrid SVC (HSVC) with these two power and control parts, used to compensate the reactive power and therefore regulates the voltage at the busbar of the electrical network and reduce the distortion of current and voltage.

The nominal source voltage is initially set at $1.004 \mathrm{pu}$. In addition, the reference voltage $\mathrm{V}_{\text {ref }}$ is fixed at $1.0 \mathrm{pu}$, the SVC is initially floating (zero current). This operating point is obtained with a TSC in operation and the TCR almost in full conduction. The source voltage is programmed with two variations (Figure 9), the first an overvoltage of $1.0125 \mathrm{pu}$, the second a voltage drop of $0.93 \mathrm{pu}$ carried out respectively in time intervals in seconds [0,1 0.4$]$ and [0.4 0.7].

The three-phase harmonic filters are: Single-Tuned, High-Pass filter, Double-tuned filter, C-type High-pass filter already described above. To optimize the efficiency of the HSVC, I used tow regulation of the effective value $\left(\mathrm{V}_{\text {mes }}\right)$ of the network voltage between phase, two regulators the PIP and the fuzzy PI. The HSVC compensator controls the fundamental voltage and sends the appropriate pulses to the 24 thyristors (6 thyristors for each phase) to obtain the susceptance required by the voltage regulation. The values of various components of the system to be simulated are shown in Figure 10. 


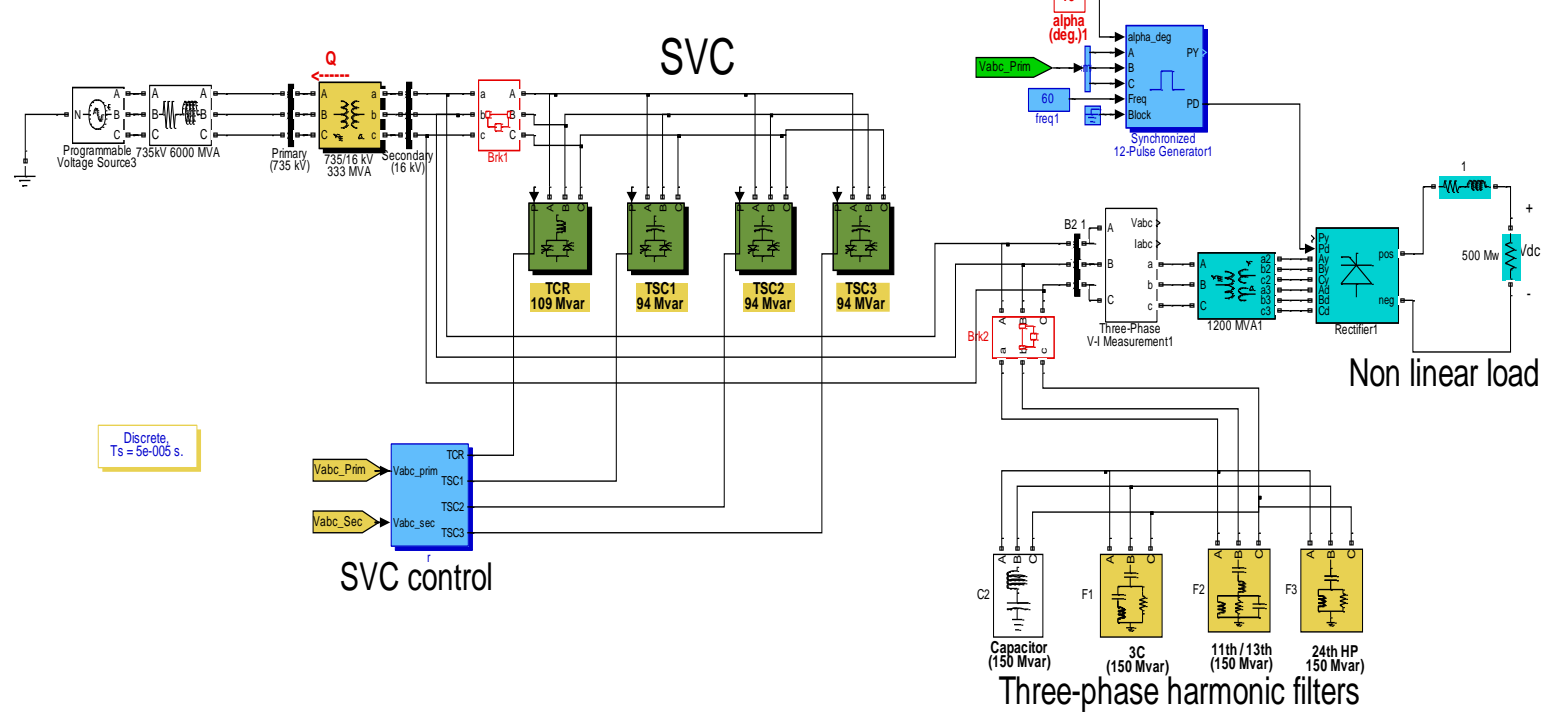

Figure 8. Overall scheme of the system to simulate in MATLAB/Simulink
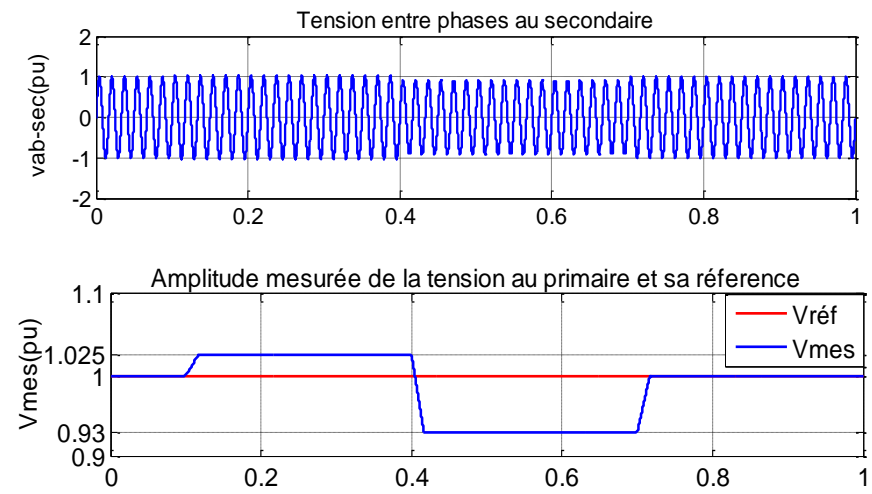

Figure 9. Voltage between phase in primary and its amplitude provided by the programmable source

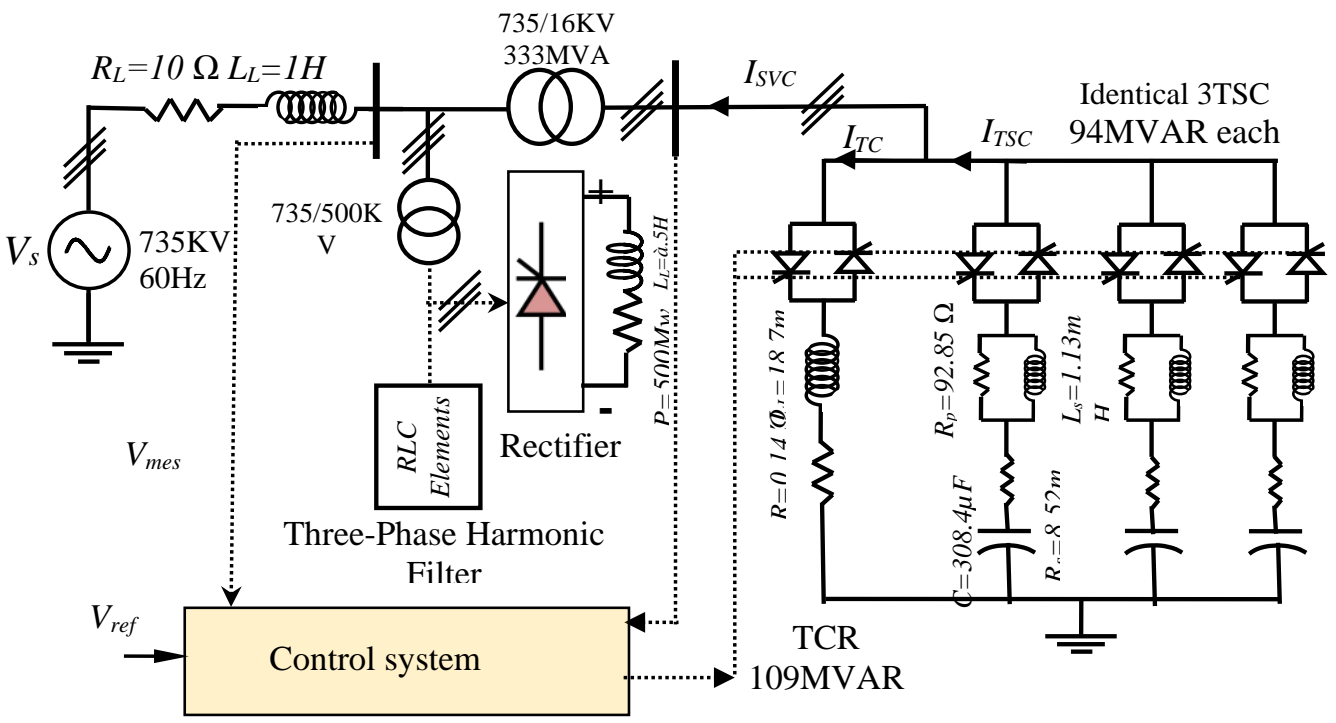

Figure 10. Overall scheme of the system to simulate (single-line diagram) 


\subsection{Simulation results (hybrid SVC disconnected)}

In this first case, we represent the shape of the source voltage, its amplitude, the voltage of the nonlinear load, their zoom, and their total harmonic distortion THD (Figure 11). The SVC and the threephase harmonic filter are disconnected.
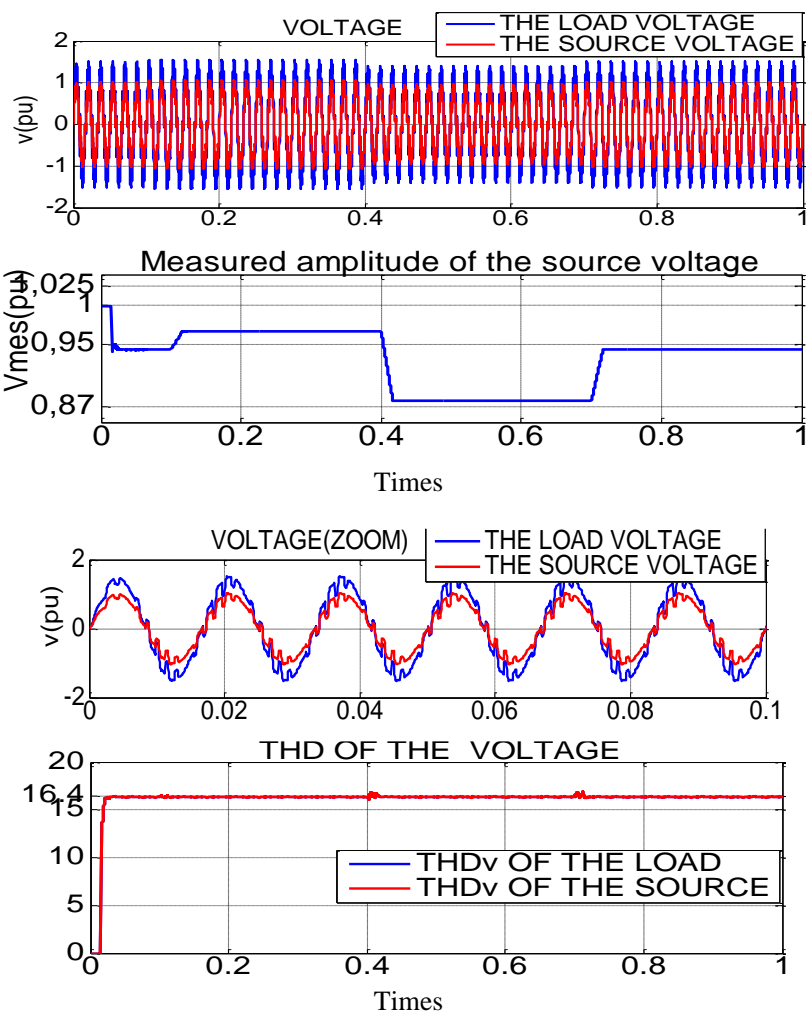

Figure 11. Source voltage, its amplitude, load voltage and their THD (total harmonic distortion)

In the same case we represent the shape of the currents of the source and of the nonlinear load, their zoom, and their total harmonic distortion THD (Figure 12).
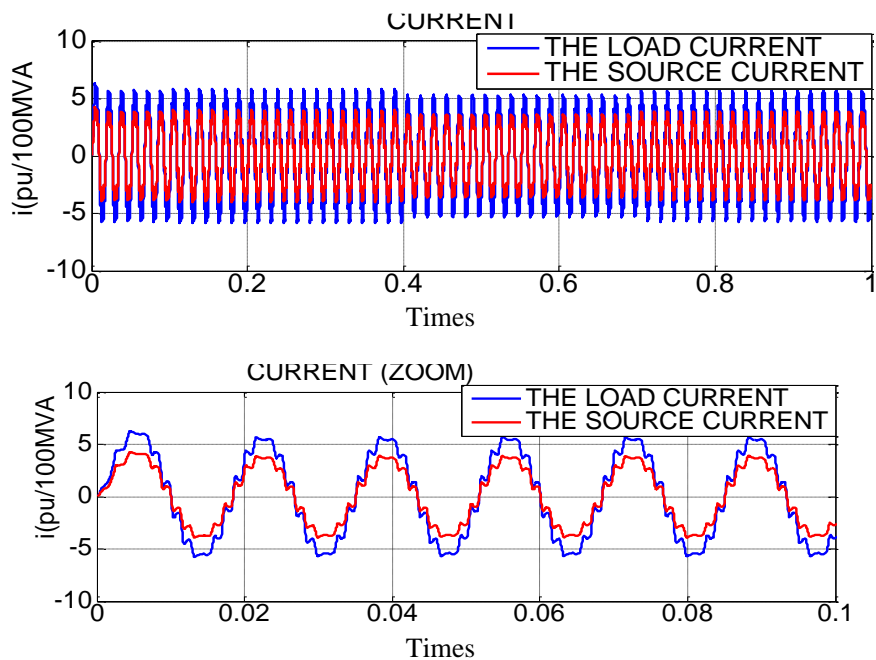

Impact of the hybrid reactive power compensator (HSVC) on the power grid .... (Abdelkader Rahmouni) 


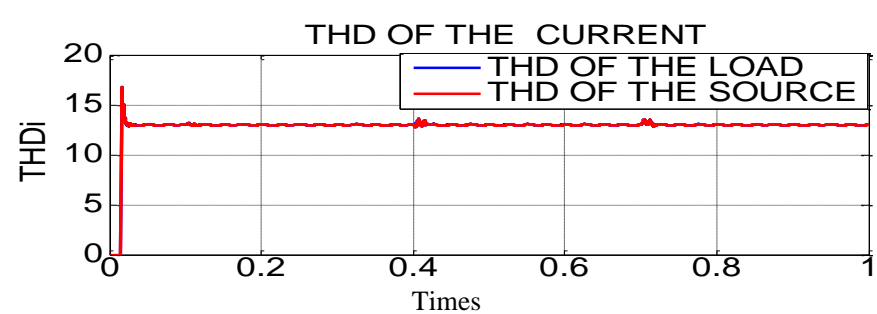

Figure 12. Currents of the source and of the nonlinear load and their THD

\subsection{Simulation results (hybrid SVC connected)}

In the second case, we represent the shape of the source voltage, its amplitude, the voltage of the nonlinear load, their zoom, and their total harmonic distortion THD (Figure 13). The SVC and the threephase harmonic filter are connected.
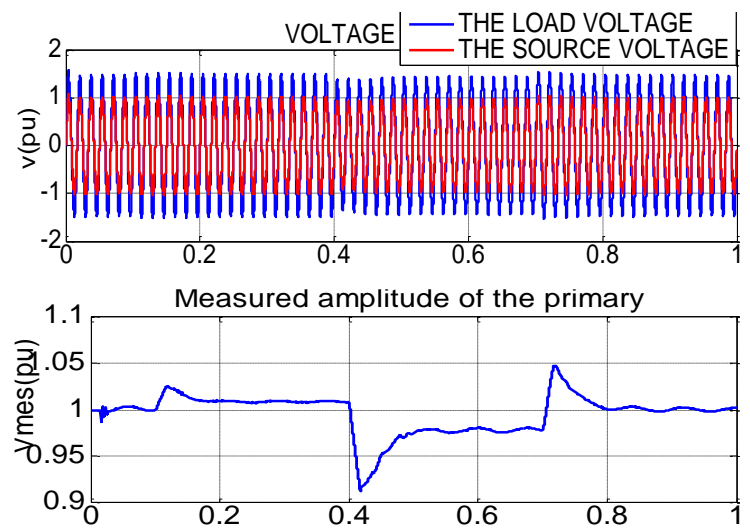

Times
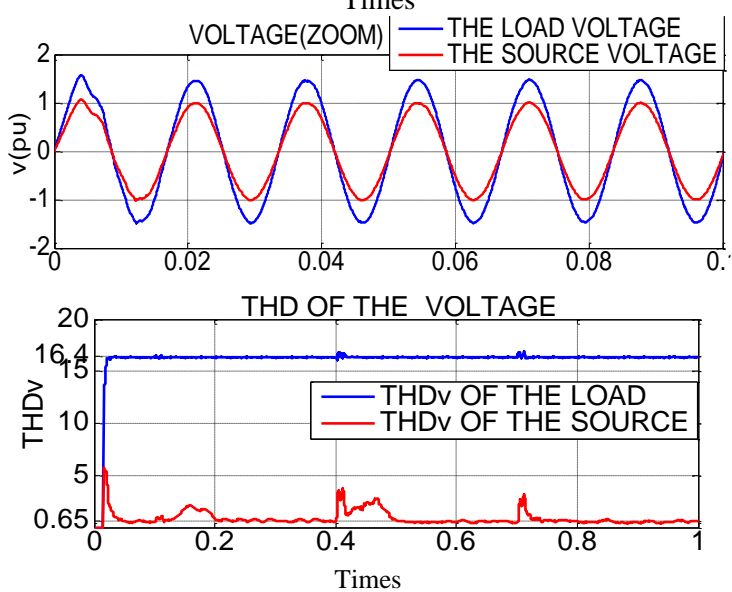

Figure 13. Source voltage, its amplitude, load voltage and their THD

In the same case we represent the shape of the currents of the source and of the nonlinear load, their zoom, and their total harmonic distortion THD also the reactive power absorbed or provided by the SVC to compensate the disturbances of the source voltage (voltage drop, overvoltage or distortion) (Figure 14). 

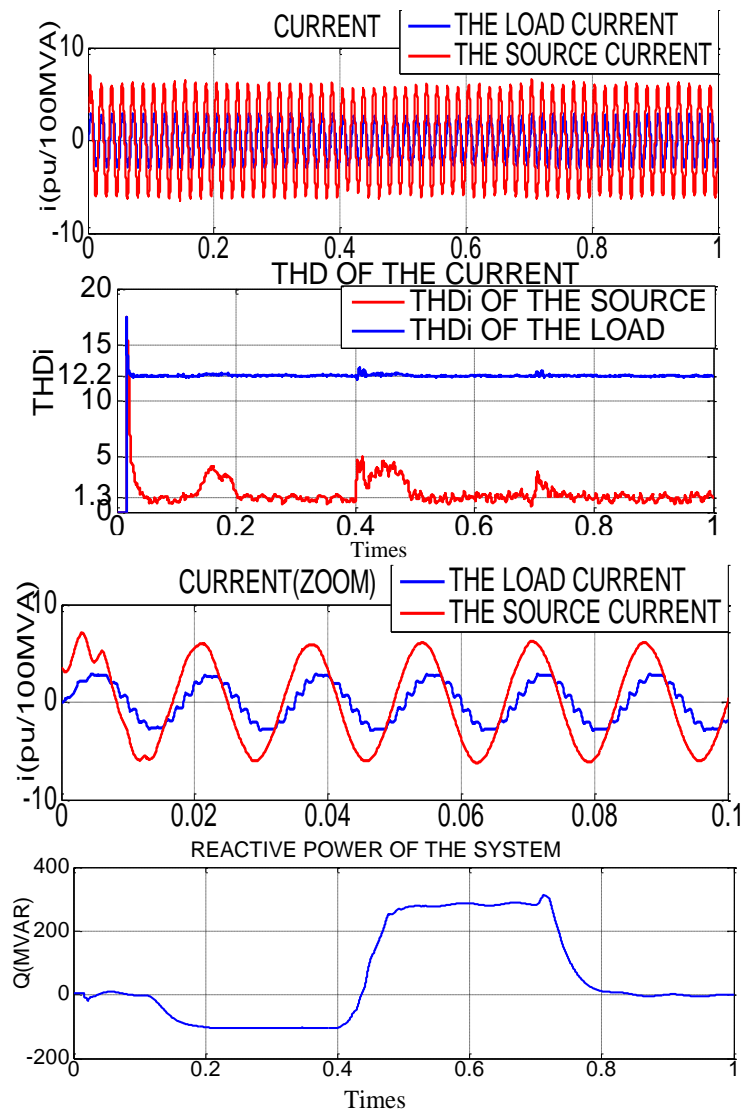

Figure 14. Currents of the source and of the nonlinear load, their THD and the reactive power absorbed or provided by the SVC

\subsection{Simulation results (SVC connected and the three-phase filter disconnected)}

In the tird case, we represent the shape of the source voltage, its amplitude, the voltage of the nonlinear load, their zoom, and their total harmonic distortion THD (Figure 15). The SVC is connected and the three-phase harmonic filter is disconnected.
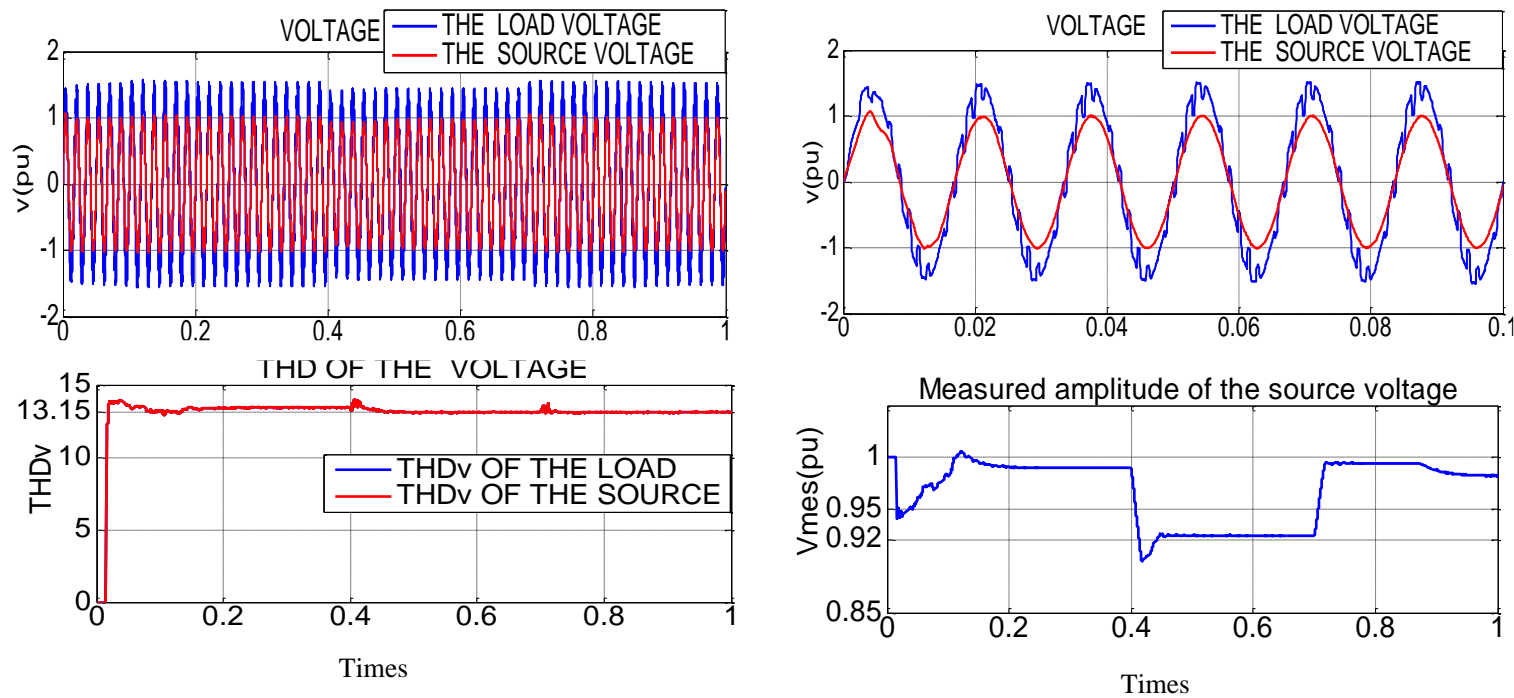

Figure 15. Source voltage, its amplitude, load voltage and their THD 
In the same case we represent the shape of the currents of the source and of the nonlinear load, their zoom, and their total harmonic distortion THD also the reactive power absorbed or provided by the SVC to compensate the disturbances of the source voltage (voltage drop, overvoltage or distortion) (Figure 16).
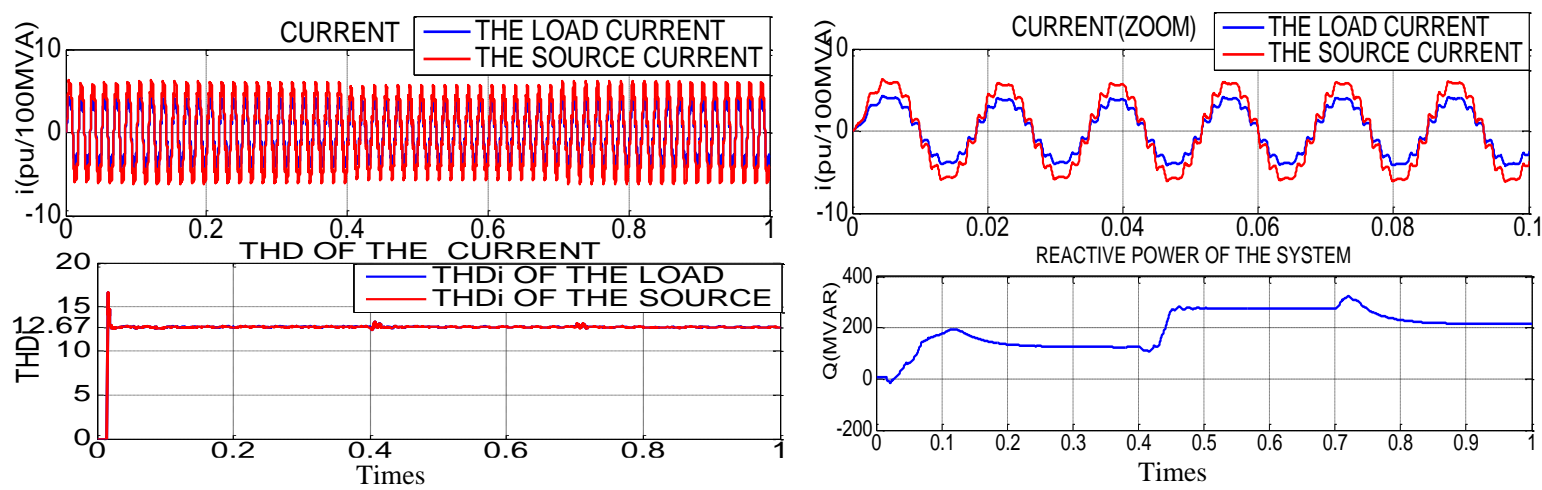

Figure 16. Currents and their THD and the reactive power absorbed or provided by the SVC

\subsection{Comparative result of the amplitude of the source voltage}

In Figure 17, we represent the shape of the amplitude of the source voltage for comparison between the three cases of simulation.

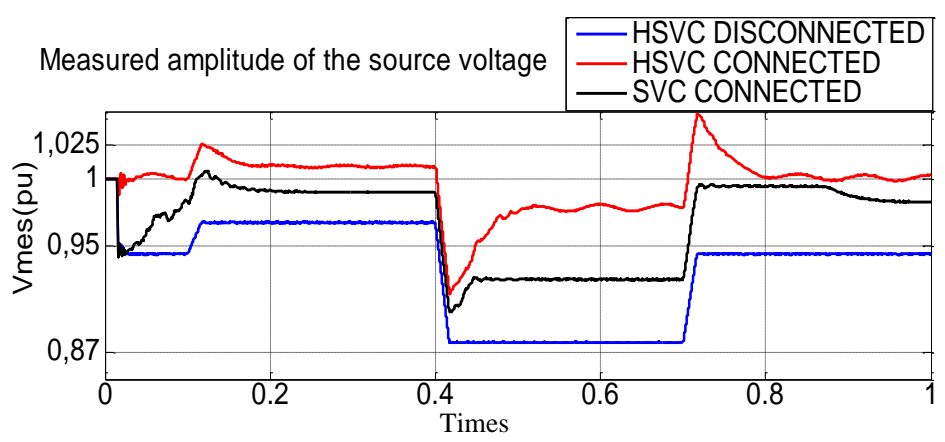

Figure 17. Comparative result of $\mathrm{V}_{\text {mes }}$ for the three cases

\subsection{HSVC behavior with the two regulators}

In Figure 18 we have represented the amplitude of the voltage source and the reactive power absorbed or provided by the SVC with the two regulators proposed, the PIP and the Fuzzy PI in order to compare these results.
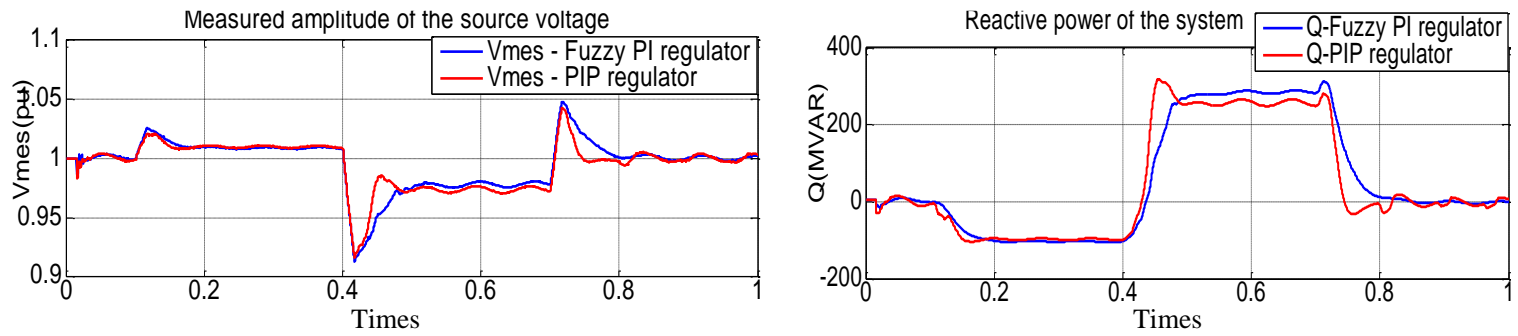

Figure 18. Source voltage amplitude and reactive power absorbed or provided by the SVC 


\subsection{Discussions results}

\subsubsection{1st case: the HSVC disconnect}

Initially, the source voltage undergoes a deep fall because of the two variations existing from the source and presents a distortion and because of the nonlinear load which generates harmonic currents and therefore consumes of two ways the reactive power. The voltage dropped in this case down to- $0.87 \mathrm{pu}$ (Figure 11 voltages and their THD (Harmonic distortion rate) and amplitude of the source voltage). So no compensation is reached by the HDVC.

\subsubsection{2nd case: the HSVC connected}

In this case, the harmonics filter eliminates harmonic currents and therefore reduces the consumption of the reactive power. The THD (Harmonic distortion rate) of current and voltage are very visibly reduced, the $\mathrm{THD}_{\mathrm{v}}$ becomes $0.65 \%$ (Figure 13 ) and the $\mathrm{THD}_{\mathrm{i}}$ becomes $1.30 \%$ (Figure 14). At $\mathrm{t}=0.1 \mathrm{~s}$, the voltage increases to $1.025 \mathrm{pu}$. The SVC reacts to deliver it to its reference by absorbing reactive power. At this point all the TSCs are out of service and the TCR is almost in full conduction. At $t=0.4 \mathrm{~s}$, the source voltage is abruptly decreased to $0.93 \mathrm{pu}$. The SVC reacts by producing reactive power, thereby increasing the voltage near its reference. At this point the three TSCs are in service and the TCR absorbs approximately $40 \%$ of the reactive power. Each time a TSC is initiated, the angle $\alpha$ of the TCR changes suddenly from 180 degrees (no conduction) to 90 degrees (full conduction). Finally, at $\mathrm{t}=0.7 \mathrm{~s}$, the busbar voltage is increased to $1.0 \mathrm{pu}$ and the reactive power of the SVC is reduced to zero (Figure 13 amplitude of the source voltage).

\subsubsection{3nd case: $\mathrm{SVC}$ connected and HF disconnected}

The SVC reacts to return the voltage to its reference by supplying the reactive power during the time interval [0.1 1] (Figure 16) reactive power of the SVC). At this point in the time interval [0.1 0.4], two TSCs are in service and in the remaining time the three TSCs are in service the TCR remains closed (the angle $\alpha$ of the TCR remains at 180 degrees (no conduction)) given the large reactive power consumed. In this case the fall is improved but it is not the most desirable. This is due to harmonic currents and the consumption of reactive power by the non-linear load.

The SVC alone without the harmonic filter does not achieve the desired compensation, the Harmonic distortion rate THDi $=12.65 \%$ of the load current and the $\mathrm{THD}_{\mathrm{v}}=12.65 \%$ of the source voltage remain unchangeable (Figure 15 and Figure 16). Finally, In general, the SVC was able to give satisfactory compensation results by using the two voltage regulators. With the PI Fuzzy regulator, the SVC gave maximum compensation and the best results compared to the PIP regulator. The PIP regulator has a shorter stabilization time compared to PI fuzzy (Figure 18).

\section{CONCLUSION}

In this work, I have tried to illustrate the usefulness, efficiency and speed of control ling voltages and reactive power, as well as eliminating harmonic currents and voltages by inserting the hybrid SVC controller. In this dispute I have described the structure of the hybrid SVC with a study of each model. The simulations are made on the SVC constituted by a TCR and three TSCs by adding an HF harmonic filter to it to become the hybrid SVC (HSVC). And to make the latter more efficient I have introduced two voltage regulators, the first is the PIP and the second is the regulator using the fuzzy PI. The results obtained show that the HSVC control device can play a very important role in the field of reactive power compensation and the control of the voltages of the different nodes. In particular, the HSVC with the fuzzy PI regulator presented more satisfactory results.

\section{REFERENCES}

[1] P. R. Kumari, "Brief Study on TSCS, SSSC, SVC Facts Device," International Journal of Advanced Research in Electrical, Electronics and Instrumentation Engineering, vol. 5, no. 8, pp. 7053-7060, Aug. 2016.

[2] Biswas Md M. and D. Kamol K., "Voltage Level Improving by Using Static VAR Compensator (SVC)," in Global Journal of researches in engineering: J General Engineering, vol. 11, no. 5, Jul. 2011.

[3] A. K. Sahoo, S. K. Sahoo, and N. Mohanty, "Modeling and Simulation of Three Phase D-SVC for Load Compensation," International Journal of Power Electronics and Drive System (IJPEDS), vol. 8, no. 1, pp. 262-271, Mar. 2017.

[4] A. Naeem and A. Atif, "Transient Stability of Power System by Static VAR Compensator (SVC) and Power System Stabilizers (PSS) using MATLAB/Simulink," SSRG International Journal of Electrical and Electronics Engineering (SSRG-IJEEE), vol. 5, no. 4, pp. 16-20, Apr. 2018.

[5] M. Singh and S. Gupta, "Optimal Placement of Facts Devices in Power System for Power Quality Improvement," International Journal of Recent Technology and Engineering (IJRTE), vol. 7, no. 6, pp. 605-610, Mar. 2019. 
[6] D. Patel and M. C. Pandya, "Voltage Stability Improvement using Static VAR Compensator (SVC) in Power System," International Journal for Scientific Research \& Development|, vol. 4, no. 11, pp. 196-198, 2017.

[7] B. Saleh, L. J. Yin, and R. Verayiah, "Voltage regulation and power loss reduction by integration of SVC in distribution networks via PSSE," International Journal of Power Electronics and Drive System (IJPEDS), vol. 11, no. 3, pp. 1579-1587, Sep. 2020.

[8] S. Chaturvedi, "Voltage Stability Improvement Using Static Var Compensators (SVC)," International Journal of Engineering Research in Electrical and Electronic Engineering (IJEREEE), vol. 3, no. 3, pp. 1-6, Apr. 2017.

[9] Z. Kamis et al., "A Review on SVC control for power system stability with and without auxiliary controller," Bulletin of Electrical Engineering and Informatics, vol. 8, no. 3, pp. 761-768, Sep. 2019.

[10] Y. Sayed, A. M. El-Sayed, and A. N. A. Elghaffar, "Multi-Shunt VAR Compensation SVC and STATCOM for Enhance the Power System Quality," Journal of Electrical Engineering, Mar. 2019.

[11] Md. S. Haque et al., "Comparative Study on the Effectiveness of ShuntFacts Devices (SVC, STATCOM) and Series Facts Device (TCSC) for the Enhancement of Transient Stability of Two Area Multi Machine Power System," International Journal of Engineering Research \& Technology (IJERT), vol. 4, pp. 1140-1145, 2015.

[12] A. Md. Rahman, "Enhancement of Voltage and power Flow by Series FACTS devices Using TCSC and SSSC," IJIRMPS, vol. 7, no. 1, pp. 40-47, 2019.

[13] B. Dipen, H. Jaydeep, and P. Desai, "Improvement of Power factor Using Thyristor Switched Capacitor (TSC)," International Journal of Innovative and Emerging Research in Engineering, vol. 5, no. 5, pp. 16-19, 2018.

[14] K. P. Panda, S. Samantaray, and S. Rout, "Prototype design of power factor correction circuit for transmission lines using Thyristor switched capacitor scheme," World Journal of Modelling and Simulation, vol. 13, no. 4, pp. 314-321, 2017.

[15] R. B. Chavan, R. M. Gadade, and R. D. Magdum, "Transient Free Tsc Compensator For Reactive Load With Closed Loop Control," International Journal of Emerging Technology and Innovative Engineering, vol. 2, no. 4, pp. 314-321, Apr. 2016.

[16] Malvik k Lad and P. Kalpesh, "Design and implementation of TSC-TCR for reactive power compensation," International Journal of Innovative and Emerging Research in Engineering, vol. 3, no. 5, pp. 59-64, 2016.

[17] T. M. Aye and S. W. Naing, "Analysis of Harmonic Reduction by using Passive Harmonic Filters," International Journal of scientific Emerging and Technology Research, vol. 3, no. 45, pp. 9142-9147, Dec. 2014.

[18] R. S. Kumar, R. S. Prakash, B. Y. Kiran, and A. Sahana, "Reduction and Elimination of Harmonics using Power Active Harmonic Filter," International Journal of Recent Technology and Engineering (IJRTE), vol. 8, no. 253, pp. 178-184, Jul. 2019.

[19] A. Rahmouni and C. Benachaiba, "Comparison of two controllers PI and IP of the voltage of a two Inverters UPQC," Applied Mechanics and Materials, vol. 313-314, pp. 508-515, 2013.

[20] A. Rahmouni, C. Benachaiba, and B. Mazari, "New Regulator PIP of the DC Voltage of the UPQC Inverters," 2nd International Conference on Mechanical, Electronics and Mechatronics Engineering (ICMEME'2013), London (UK), Jun. 2013, pp. 80-84.

[21] Sureshkumar S. and Kalyanasundaram M., "Intelligent technique for FACTS devices to enhance the power system stability in large bus system," Transactions on Engineering and Sciences, vol. 1, no. 4, pp. 72-77, Nov. 2013.

[22] B. L. Nayak, "Desing, Modeling and Simulation of VAR Compensation Using Fuzzy Control Svc in Long Transmission Line," International Journal of Engineering and Advanced Technology (IJEAT), vol. 3, no. 03, pp. 278-283, Feb. 2014.

[23] A. H. Sekhar et al., "Novel hybrid optimization techniques for analyzing the performance of transmission linesusing SVC device," International Journal of Electrical Engineering \& Technology (IJEET), vol. 11, no. 1, pp. 1-14, 2020.

[24] K. Shashikumar, C. Venkataseshaiah, and K. S. Sim, "Fuzzified Single Phase Automatic Sequential Reactive Power Compensation with Minimized Switches," TELKOMNIKA, vol. 16, pp. 889-899, Apr. 2017.

\section{BIOGRAPHY OF AUTHOR}

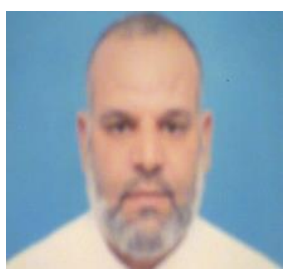

Abdelkader RAHMOUNI was born in Bechar, Algeria, in 1968. He received the Engineer degree in Electrotechnics in 1992 from Sidibelabes University, Algeria and the Magister degree in Energetic Physics from Bechar University, Algeria, in 2008. Obtained his Doctorate degree in Electrical Engineering from Bechar university in 2015. He is currently Teacher in Bechar University, Algeria. His main research activity is focused on energy quality Flexible AC Transmission systems (FACTS), power electronics, process control and renewable energy 